\title{
Archean biogeochemical processes, Dharwar Craton, India: isotopic and geochemical evidences for the early record of life
}

\author{
CHAKRAVADHANULA MANIKYAMBA
}

National Geophysical Research Institute (Council of Scientific and Industrial Research), Uppal Road, Hyderabad 500 007, India

Email: cmaningri@gmail.com

Inspite of vigorous plate tectonic processes, metamorphism and alteration, the biogenic signatures are well preserved in the sedimentary rocks of Paleo to Mesoarchean greenstone belts of Dharwar Craton. The stromatolitic carbonates have varied morphological features and are associated with Fe-Mn deposits and carbonaceous shales. The $\mathrm{U}-\mathrm{Pb}$ ages of the detrital zircons from the stromatolitic carbonates of Sandur and Chitradurga greenstone belt from the Dharwar Craton range from $3508 \pm 29 \mathrm{Ma}$ to $2926 \pm 36$ $\mathrm{Ma}$ and $3426 \pm 26 \mathrm{Ma}$ to $2650 \pm 38 \mathrm{Ma}$ respectively suggesting Paleo to Neoarchean sources.
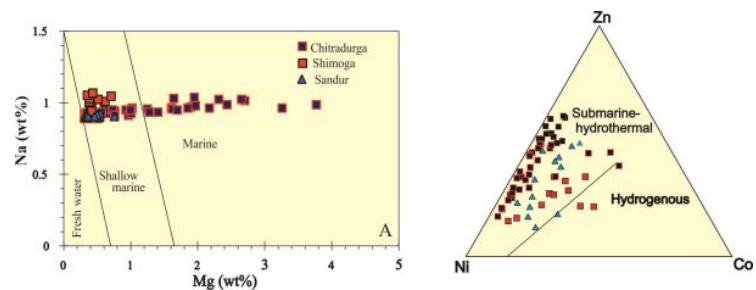

Fig. Marine and hydrothermal signatures in Mn ores

These stromatolites exhibit $\mathrm{La}, \mathrm{Eu}$ and $\mathrm{Gd}$ positive anomalies and MREE/HREE ratios indicative of fluctuating ocean water conditions (oxic/anoxic; acidic/alkaline) and terrigenous/hydrothermal inputs in a volcanically active environment in the Dharwar Craton during the Neoarchean times. The $\mathrm{Mn}$ ores associated with them also exhibit negative $\mathrm{Ce}$ anomalies and shallow marine to marine environment with hydrothermal signatures. The carbonacesous shales from Sandur and Chitradurga display low order negative $\mathrm{Ce}$ anomalies with positive $\mathrm{Eu}$ anomalies. The negative to positive $\delta^{13} \mathrm{C}$ of the stromatolites indicate local redox and temperature variations in the Archean oceans. The negative $\delta^{18} \mathrm{O}$ endorse fluctuating Archean seawater temperatures ranging from $25^{\circ}-75^{\circ} \mathrm{C}$ with variable influence of hydrothermal input. The Mn formations with predominant hydrothermal signatures and the carbonaceous shales with highly negative $\delta^{13} \mathrm{C}$ are supportive of the Archean biogeochemical processes in the Dharwar Craton. 
This abstract is too long to be accepted for publication.

Please revise it so that it fits into the column on one page. 